\title{
Fluorescence in situ hybridization analysis of endosymbiont genera reveals novel infection patterns in a tomato-infesting Bemisia tabaci population from Brazil
}

\author{
Rosana Blawid $^{1}$ - Fabrício S. Morgado ${ }^{1} \cdot$ Caroline A. Souza $^{1} \cdot$ Renato O. Resende $^{1,2}$. \\ Leonardo S. Boiteux ${ }^{3}$ • Rita C. Pereira-Carvalho ${ }^{2}$
}

Received: 17 March 2015 / Accepted: 11 May 2015 / Published online: 3 July 2015

(C) Sociedade Brasileira de Fitopatologia 2015

\begin{abstract}
The Bemisia tabaci cryptic species complex harbors a diversified flora of primary and secondary endosymbionts, which plays crucial roles in many aspects of the insect biology. The endosymbiont infection pattern is dependent upon many factors, including host plant and geographic origin. In Brazil, the invasion of B. tabaci Middle East-Asia Minor-1 (MEAM 1) populations was observed in tomato (Solanum lycopersicum L.) fields in the 1990s, which was followed by severe begomovirus epidemics. Here we confirmed the vertical transmission of "Candidatus Portiera" and the localization of secondary endosymbionts in distinct $B$. tabaci developmental stages. Hamiltonella defensa was detected in bacteriocytes but also scattered in the leg muscles as well as in the male heads. Wolbachia-specific signals were found in eggs, nymphs, male adults, and female gonads in predominant association with bacteriocytes. These results were somewhat surprising since Wolbachia infection is rarely found in MEAM 1 populations from the Old World. Our results reinforce the notion that endosymbiont infection pattern may vary according to the insect population, gender, developmental stage, and geographic origin. This characterization will provide tools to study the endosymbiont function in the transmission
\end{abstract}

Section Editor: F. Murilo Zerbini

Rita C. Pereira-Carvalho

rcpcarvalho@unb.br

1 Departamento de Biologia Celular, Instituto de Biologia, Universidade de Brasília (UnB), 70910-900 Brasília, DF, Brazil

2 Departamento de Fitopatologia, Universidade de Brasília (UnB), Área de Virologia Vegetal, 70910-900 Brasília, DF, Brazil

3 National Center for Vegetable Crops Research (CNPH), Embrapa Hortaliças, CP 0218, 70359-970 Brasília, DF, Brazil ability/efficiency of a complex of tomato-infecting bipartite begomoviruses by $B$. tabaci under Neotropical conditions.

Keywords Endosymbionts · Bemisia tabaci MEAM 1 . Wolbachia

\section{Introduction}

The whitefly [Bemisia tabaci (Genn.) (Hemiptera: Aleyrodidae)] cryptic species complex is among the most important pests in a wide range of economically important plants such as tomatoes (Solanum lycopersicum L.), leaf vegetables, cucurbits, legumes, cassava, cotton, and ornamental plants (De Barro et al. 2011). More than one thousand of whitefly species have been described (Brown 2007), but only three are recognized as plant virus vectors (Thompson 2011). Bemisia tabaci is a very efficient vector of viral species from the genera Begomovirus (family Geminiviridae), Torradovirus (Secoviridae), Ipomovirus (Potyviridae), and Crinivirus (Closteroviridae) (Navas-Castillo et al. 2011). Nymphs and adults of B. tabaci can also induce physiological disorders in many host plants, including the silverleaf syndrome in cucurbits, tomato irregular ripening, and broccoli light stalk (Thompson 2011).

The diversity of $B$. tabaci was initially categorized as biotypes, which are populations that share similar morphological characteristics as well as biological features such as virustransmission ability/efficiency, host range, host-specific adaptation, life history traits, tolerance to adverse climatic conditions, induction of specific plant physiological disorders and tolerance to insecticides (Berry et al. 2004; De Barro et al. 2011; Navas-Castillo et al. 2011). Currently, B. tabaci is recognized as a genetically diverse complex of distinct cryptic species (De Barro et al. 2011). Studies based upon the mitochondrial cytochrome oxidase I (COI) gene sequence phylogeny 
indicated the worldwide occurrence of at least 31 cryptic species in 11 high-level genetic groups (Dinsdale et al. 2010; Lee et al. 2013). The cosmopolitan B. tabaci species from Middle EastAsia Minor 1 (MEAM 1) is a major pest and an important vector of viruses in many tropical and subtropical areas (De Barro et al. 2011; Navas-Castillo et al. 2011).

Distinct $B$. tabaci cryptic species and even geographically isolated populations may differ in relation to the taxonomic diversity and relative frequency of the endosymbionts that they may harbor (Thompson 2011; De Barro et al. 2011). Endosymbionts are organisms that live within other organisms establishing distinct types of interactions with their hosts (Buchner 1965; Moran and Baumann 1994). In fact, whiteflies and other groups of insects house a diversified bacterial community (Baumann et al. 1993; Chiel et al. 2007; ZchoriFein and Brown 2002; Zchori-Fein et al. 2014), which includes the widespread obligate (primary) endosymbiont "Candidatus Portiera aleyrodidarum" (here referred to as " $\mathrm{Ca}$. Portiera") and so far seven secondary (facultative) endosymbiont genera viz. Arsenophonus, Cardinium, Fritschea, Hamiltonella defensa, Rickettsia, and Wolbachia (Clark et al. 1992; Nirgianaki et al. 2003; Thao and Baumann 2004; Everett et al. 2005; Gottlieb et al. 2006; Chiel et al. 2009; Ahmed et al. 2013). More recently, an Orientia-like organism (Bing et al. 2013) was also included in the list as Candidatus Hemipteriphilus asiaticus.

The endosymbiont flora plays important roles in many aspects of the host biology in a wide array of insects (Chiel et al. 2009). There are evidences that these interactions are crucial for insect fitness, survival, and nutrition (Moran et al. 2003). For example, the presence of $H$. defensa may confer host resistance against parasitoids (Ferrari etal. 2004; Bensadia etal. 2005) and plays a role in accelerating $B$. tabaci rate of growth, especially during periods of host nutritional stress (Su et al. 2014). " $C a$. Portiera" was found to be a major supplier to its insect host diet of essential amino acids (Jiang et al. 2013) and carotenoids (Santos-Garcia et al. 2012). Endosymbiotic associations may also be involved in modulating host immunocompetence variation (Braquart-Varnier et al. 2008). On the other hand, negative impacts of endosymbiont flora have also been reported. For example, the presence of Rickettsia is associated with increased susceptibility of $B$. tabaci to insecticides (Kontsedalov et al. 2008). In extreme cases, the symbiotic nature may movetowards highly virulent parasitism (e.g., Wolbachia-Drosophila), causing degeneration and early death of the insect host (Min and Benzer 1997). Insect endosymbionts can also manipulate the reproduction rate of their hosts and enhance their own rate of transmission via distinct sex-ratio-distorting mechanisms such as male-killing activities, cytoplasmic incompatibility, and feminization (Weeks et al. 2003).

The primary endosymbiont " $\mathrm{Ca}$. Portiera" has been found across distinct $B$. tabaci populations, plant hosts, and insect gender (Pan et al. 2012b). Complete genome assembly was carried out using genomic DNA from two " $C a$. Portiera" strains obtained in association with MEAM 1 and $B$. tabaci Mediterranean subgroup Q (MED Q) species. These analyses indicated that these strains have a $351-\mathrm{kb}$ circular molecule and the genomes of the two groups share around $99.8 \%$ identity (Jiang et al. 2013). Even though displaying almost identical gene repertoire and order, some species-specific genetic differences were identified (Santos-Garcia et al. 2012; Jiang et al. 2013).

There is a growing amount of evidences that some secondary endosymbionts might have group-specific incidence. For instance, $H$. defensa has been found associated with populations of B. tabaci from the MEAM 1 group, whereas Arsenophonus and Rickettsia were found indistinctly in MEAM 1 and MED Q species. On the other hand, Wolbachia infection was either not reported or found at very low frequency in $B$. tabaci MEAM 1 populations from the Old World (Chiel et al. 2007; Chu et al. 2011; Pan et al. 2012a).

Frequency and infection dynamics of secondary endosymbionts in whiteflies are variable according to host species, geographic area, insect species, and the prevalent gender in the field populations (Chu et al. 2011; Pan et al. 2012b). Percentage of Wolbachia infection was very low in MEAM 1 species and MED Q field populations in China and co-infection with others secondary endosymbionts was never found (Pan et al. 2012a). In Israel, Wolbachia associations with bacteriocytes were found in individuals from the MED Q group, but it was not found in samples from the MEAM 1 (Gottlieb et al. 2008). On the other hand, MED Q populations from Croatia showed localization of Wolbachia only inside the bacteriocytes and not in other organ at any developmental stage (Škaljac et al. 2010). The co-infection levels of secondary endosymbionts in B.tabacipopulations may also change according to the species (Škaljac et al. 2010; Škaljac et al. 2013). Populations of MEAM 1 from China showed a significantly higher frequency of double (RickettsiaHamiltonella and Rickettsia-Cardinium) and triple (RickettsiaHamiltonella-Cardinium) co-infections than that found on MED Q populations (Pan et al. 2012a).

In Brazil, B. tabaci (former biotype A-New World species, Dinsdale et al. 2010) was first reported in the late 1960s colonizing cotton and legume crops. At that time, the begomovirusinduced damages were restricted to the "golden mosaic disease" of field beans (Costa et al. 1973). The invasion of B. tabaci MEAM 1 populations was confirmed in tomato fields in the 1990s, which was followed by severe begomovirus epidemics (Ribeiro et al. 1994). The rapid spread of the MEAM 1 into the country in association with its wide host range allowed for the natural transfer of new begomoviruses from weeds and/ornative Solanaceae species to cultivated tomato, intensifying the selection pressure towards a higher number of novel begomoviruses in this crop (Ribeiro etal. 2003; Fernandes etal.2008; Fernandes 2010). Studies on diversity of $B$. tabaci populations associated with the tomato crop are now under way in Brazil (Ribeiro et al. 
2003; Fernandes 2010; Marubayashi et al. 2013). These studies are indicating that populations closely related to $B$. tabaci MEAM 1 are predominant in the Brazilian tomato fields.

Although whitefly endosymbionts have been object of many recent studies worldwide, there is an overall few works documenting the endosymbiont diversity in whiteflies populations colonizing the tomato crop in Brazil (Marubayashi et al. 2013, 2014). Currently, the secondary endosymbiont Wolbachia is being a subject of extensive studies in many different organisms, mainly because it can manipulate the reproduction rate of their hosts and enhance their own rate of transmission and therefore might serve as a biological control agent (Mitsuhashi et al. 2002). During preliminary surveys, we faced a surprising fact that Wolbachia could be detected at high frequency in nymphs and eggs of our experimental tomato-infesting B. tabaci population. In this context, considering the increase of interest in localizing and detecting endosymbionts in whiteflies populations around the world, we decided to study the presence of three genera (" $\mathrm{Ca}$. Portiera", Wolbachia, and H. defensa) in a representative tomatoinfesting B. tabaci MEAM 1 population in distinct developmental stages using whole-mount fluorescence in situ hybridization analysis (FISH) analysis. "Ca. Portiera" (a primary endosymbiont with well-established localization in the bacteriocytes) was employed as an internal control in these FISH assays.

\section{Materials and methods}

\section{Bemisia tabaci MEAM 1 population and colony maintenance}

Begomovirus-free $B$. tabaci MEAM 1 colony was originally obtained from infested tomato plants under field conditions in Brasília-DF (Central Brazil). This population was then reared on virus-free cabbage (Brassica oleracea var. capitata) plants during approximately 6 months. This insect population was kept into isolated cages at the greenhouse system of the Experimental Biology Station (EBS) of UnB in Brasília-DF, Brazil. These host plants were cultivated in 2 L-plastic pots filled with commercial solid substrate (Bioplant ${ }^{\circledR}$, Nova Ponte-MG, Brazil). The average temperature in the greenhouse was of $28 \pm 2{ }^{\circ} \mathrm{C}$ and the relative air humidity was $69.7 \pm 5 \%$.

\section{DNA extraction and PCR assay for B. tabaci identification}

Total genomic DNA was purified from a sample of ten whitefly adults using a CTAB $2 \mathrm{X}$ buffer and organic solvents essentially as described by Boiteux et al. (1999). Sequence analyses were carried out using a partial cytochrome oxidase subunit I (COI) mitochondrial gene segment, which is rich in genetically informative single nucleotide polymorphisms. The $700 \mathrm{bp}$ target PCR product was amplified using the prime pair: C1-J-2195 (5'-TTG ATT TTT TGG TCA TCC AGA AGT-3') and L2-N-3014 (5'-TCC AAT GCA CTA ATC TGC CAT ATT A-3') (Simon et al. 1994). PCR amplification of individual DNA samples was carried and amplicons were purified from the gel using the PureLink (Invitrogen) purification Kit prior to direct sequencing. Sequencing was done at an ABI 3100 (Applied Biosystems) sequencer from the Genomic Analysis Lab (at Centro Nacional de Pesquisa em Hortaliças, CNPH) located in Brasília-DF, Brazil. Phylogenetic and molecular evolutionary analyses were conducted using MEGA version 6 (Tamura et al. 2013). Multiple sequence alignments were constructed using Clustal W (Thompson et al. 1994). Sequences reported by Dinsdale et al. (2010) were downloaded in addition to our sequenced amplicon (accession number KM013848). Adjustments were performed manually and when necessary, ends of the sequences were trimmed. Phylogenetic reconstruction was performed using the Maximum Likelihood method, with 1000 Bootstrap replications, defined by the substitution model of Hasegawa et al. (1985), (HKY85) and Gamma distributed with Invariant sites $(\mathrm{G}+\mathrm{I})$. MrBayes 3.1 was used for Bayesian phylogenetic inference (Ronquist and Huelsenbeck 2003). Analyses were run for 10 million generations by using four Markov chains and sampling every thousand generations. At the end of each run the average standard variation of split frequencies was below 0.01 . Runs converged with the potential scale reduction factor (PSRF) at 1.0 for all parameters. Tree was visualized with FigTree (FigTree, 2006-2009, A. Rambaut).

\section{Endosymbiont genomic DNA extraction, PCR detection,} and sequence characterization

Total genomic DNA extraction was carried out essentially as described by Aljanabi and Martinez (1997) and Santos et al. (2003), but with some minor modifications. Successful genomic DNA extractions of a single to up ten whitefly adults were obtained after increasing the Proteinase K $(50 \mu \mathrm{L} / \mathrm{mL})$ volume in the extraction buffer from $1 \mu \mathrm{L}$ to $3.5 \mu \mathrm{L}$. Amplification was performed in $12.5 \mu \mathrm{L}$ as described previously by Zchori-Fein and Brown (2002) and Zhou et al. (1998), using the specific primer pairs listed in Table 1. Sequencing was done at an ABI 3100 (Applied Biosystems) sequencer apparatus from the Genomic Analysis Lab (at $\mathrm{CNPH}$ ) located in Brasília-DF, Brazil.

\section{Whole-mount fluorescence in situ hybridization (FISH) analyses}

Whole-mount FISH of the samples (obtained from distinct B. tabaci MEAM 1 developmental stages) was performed 
Table. 1 PCR primers employed for detection of the obligate " $C a$. Portiera" and for two facultative endosymbionts (Wolbachia and $H$. defensa) in the representative Bemisia tabaci MEAM 1 population from tomatoes in Brazil

\begin{tabular}{|c|c|c|c|c|}
\hline Endosymbiont & Primer code and genomic regions & Primer pairs and their 5' -3 ' sequence & Amplicon size (bp) & PCR Annealing $\mathrm{T}\left({ }^{\circ} \mathrm{C}\right)$ \\
\hline \multirow[t]{2}{*}{ "Ca. Portiera"1 } & Forward 28 Reverse & TGCAAGTCGAGCGGCATCAT & \multirow[t]{2}{*}{$1000-1100$} & \multirow[t]{2}{*}{$54{ }^{\circ} \mathrm{C}$} \\
\hline & $1098(16 \mathrm{~S}$ rDNA $)$ & AAAGTTCCCGCCTTATGCGT & & \\
\hline \multirow[t]{2}{*}{ Wolbachia $^{2}$} & Forward wsp 81 & TGGTCCAATAAGTGATGAAGAAAC & \multirow[t]{2}{*}{$590-625$} & \multirow[t]{2}{*}{$55^{\circ} \mathrm{C}$} \\
\hline & Reverse wsp691 (wsp gene) & AAAAATTAAACGCTACTCCA & & \\
\hline \multirow[t]{2}{*}{ Hamiltonella defensa ${ }^{1}$} & Forward Ham & TGAGTAAAGTCTGGAATCTGG & \multirow[t]{2}{*}{700} & \multirow[t]{2}{*}{$60^{\circ} \mathrm{C}$} \\
\hline & Reverse Ham (16SrDNA) & AGTTCAAGACCGCAACCTC & & \\
\hline
\end{tabular}

${ }^{1}$ Zchori-Fein \& Brown (2002)

${ }^{2}$ Zhou et al. (1998), Holden et al. (1993)

essentially as described by Gottlieb et al. (2006) using endosymbiont-specific probes (Table 2) and analyzed under a confocal laser scanning microscope (Leica model TCS SP5). Briefly, eggs, adults, and nymphs of $B$. tabaci were collected from the abaxial leaf surface of cabbage plants with the aid of a stereomicroscope (20X magnification) and then transferred to microcentrifuge tubes containing Carnoy's fixative (chloroform: ethanol: glacial acetic acid, 6:3:1) and left overnight $(12 \mathrm{~h})$ at a refrigerator $\left(4{ }^{\circ} \mathrm{C}\right)($ Gottlieb et al. 2006). Carnoy's fixative was removed while keeping the insect samples within the microcentrifuge tubes. After that, ethanoldiluted $\mathrm{H}_{2} \mathrm{O}_{2}(6 \%)$ was added (for at least $2 \mathrm{~h}$ ) to the tubes aiming to de-stain the insect tissues. This step is crucial to inactive autofluorescent pigments as well as endogenous enzymes (e.g., RNAses) present in the insect bodies. Next, the $\mathrm{H}_{2} \mathrm{O}_{2}$ was completely removed and the insect samples were washed with absolute ethanol. The samples were kept on ethanol up to the hybridization procedure. In the next step, the ethanol was removed and the insect samples were washed with the hybridization solution (20 mM TRIS-HCL pH 8.0; $0.9 \mathrm{M} \mathrm{NaCl} ; 0.01 \% \mathrm{SDS} ; 30 \%$ formamide) for $30 \mathrm{~min}$. The endosymbiont-specific probes (Table 2 ) were added (10 $\mathrm{pmol} / \mathrm{mL}$ ) to the hybridization buffer. The samples were allowed to hybridize for at least $12 \mathrm{~h}$ under room temperature and dark conditions. The insect samples were removed from the microcentrifuge tubes and then washed for $5 \mathrm{~min}$ with the hybridization solution (but without SDS). Stained samples were carefully transferred slides and analyzed under a confocal laser scanning microscope (Leica model TCS SP5, single sequential scan images for $\mathrm{Cy} 3$ and $\mathrm{Cy} 5$ probes). Cy 3 was excited with $543 \mathrm{~nm}$ (emission 560-590 nm) and Cy5 with $633 \mathrm{~nm}$ (emission 670-700 nm). Signal quantification was performed using ImageJ (National Institutes of Health, Bethesda, MD). Specificity of stained samples was confirmed by using the following internal controls: RNAse digested samples, samples containing only hybridization solution without probe, and samples without any treatment. Antibiotic treatments cannot eliminate secondary endosymbionts in a specific manner and they also induce adverse effects on the insect host fitness (Ahmed et al. 2010; Ruan et al. 2006). Therefore, controls with antibiotic treatments were not employed in our experimental whitefly population. Negative controls were carried out according to previous FISH analyses as recommended by Gottlieb et al. (2006, 2008). "Ca. Portiera" (a primary endosymbiont with wellknown localization in the bacteriocytes) was employed as an internal control in these FISH assays. Quantitative analysis of co-localization of the single sequential scan images was performed using ImageJ (National Institutes of Health, Bethesda, MD) and the Coloc-2 plugin with a sample of 50 individuals of each $B$. tabaci developmental stage. Five samples were taken in each image of each $B$. tabaci developmental stage the "Ca. Portiera" and Wolbachia combination. These values were used to calculate the means and the Pearson's correlation coefficient values. Student's onesample $t$-test was used to test the significance of Pearson's correlation coefficient measurements (McDonald and Dunn 2013) of "Ca. Portiera" and Wolbachia co-localization. All statistical analyses were performed using the software package Statistica v. 7.0.61.0 (StatSoft, Inc.).
Table. 2 Probes employed in the fluorescence in situ hybridization assays for detection of " $\mathrm{Ca}$. Portiera" and two secondary endosymbionts (Wolbachia and H. defensa) in the bodies of all developmental stages of a representative Bemisia tabaci MEAM 1 population from tomatoes in Brazil. Probes were labeled with either the fluorophore $\mathrm{Cy} 3$ or the fluorophore $\mathrm{Cy} 5$

\begin{tabular}{llll}
\hline Probe/fluorophor code & Target endosymbiont & Probe sequence 5'-3' & Reference \\
\hline BTP1-Cy3 & "Ca. Portiera” & TGTCAGTGTCAGCCCAGAAG & Gottlieb et al. (2006; 2008) \\
BTH-Cy5 & H. defensa & CCAGATTCCCAGACTTTACTCA & Gottlieb et al. (2008) \\
W2-Cy5 & Wolbachia & CTTCTGTGAGTACCGTCATTATC & Mitsuhashi et al. (2002) \\
\hline
\end{tabular}




\section{Results and discussion}

\section{Bemisia tabaci species identification via sequence analysis of the cytochrome oxidase subunit I (COI) mitochondrial gene}

A single amplicon of expected size ( $\approx 700 \mathrm{bp})$ was purified and sequenced in both directions. Using maximum likelihood analysis of the COI gene segment, which is rich in genetically informative single nucleotide polymorphisms, allow us to unequivocally classify our population as belonging to the cosmopolitan B. tabaci MEAM 1 group (Supporting Information $\mathrm{S} 1$ ), which is so far the predominant tomato-infesting whitefly species in Brazil (Marubayashi et al. 2013). BLAST analysis showed $100 \%$ identity with one $B$. tabaci MEAM 1 population (named as population Jo-122) reported on tomato plants in Jordan (GenBank accession KC789961.1). Our results are in agreement with the phylogenetic tree generated by Dinsdale et al. (2010) in which our sequence (GenBank accession KM013848) clustered to the same clade within the MEAM 1 group. This Brazilian B. tabaci MEAM 1 population was employed in all subsequent assays.

\section{PCR detection and amplicon sequence analysis of Wolbachia and $\boldsymbol{H}$. defensa associated with the tomato B. tabaci MEAM 1 population}

Single PCR amplicons of the expected size were obtained for each of the three endosymbiont-specific primer pairs. Table 3 shows the results obtained from the PCR procedures. Sequence analysis of the Wolbachia, and $H$. defensa-specific amplicons displayed identity values ranging from $97-100 \%$ with sequences available at GenBank. H. defensa amplicons were visualized in all 12 female and 12 male individual

Table 3 Relative frequency of endosymbiont-specific fluorescence in situ hybridization probe signals visualized in the bodies of distinct developmental stages of a representative Bemisia tabaci MEAM 1 population from tomatoes in Brazil and confirmed via PCR. Specific probes and hybridization assays were carried out to detect the one obligate " $\mathrm{Ca}$. Portiera" and two facultative (secondary) endosymbionts (Wolbachia and H. defensa)

\begin{tabular}{lllll}
\hline Endosymbionts & Adult Female & Adult Male & Nymphs & Eggs \\
\hline Wolbachia (FISH) & $20 / 10^{\mathrm{a}}$ & $20 / 04$ & $20 / 16$ & $20 / 17$ \\
Wolbachia (PCR) & $12 / 10^{*}$ & $12 / 05$ & n.d & n.d \\
Ca. Portiera (FISH) & $20 / 10$ & $20 / 03$ & $20 / 19$ & $20 / 18$ \\
Ca. Portiera (PCR) & $12 / 12$ & $12 / 11$ & n.d & n.d \\
Hamiltonella (FISH) & $20 / 06$ & $20 / 02$ & $10 / 05$ & $10 / 05$ \\
Hamiltonella (PCR) & $12 / 12$ & $12 / 12$ & n.d & n.d \\
\hline
\end{tabular}

a Number of evaluated samples in each B. tabaci developmental stage / number of positive samples (= detection of probe-specific signals). n.d not determined samples (100\%). Wolbachia genomic segments were amplified from ten out of 12 female samples $(83.3 \%)$ and from five out of 12 male adult samples ( $41.6 \%)$, indicating higher frequencies of Wolbachia in female than in male adults. These results are in agreement with that obtained with the FISH analysis. Also, we were able to detect Wolbachia via FISH in 80 to $85 \%$ of nymph and egg samples. Hence, is left for future work the verification if Wolbachia does alter sex ratio on this population.

\section{Vertical transmission of " $\mathrm{Ca}$ Portiera" in the Brazilian B. tabaci MEAM 1 population}

The primary (obligate) endosymbiont " $\mathrm{Ca}$. Portiera" was detected in $B$. tabaci eggs and in nymphs in association with bacteriocytes, which are large polyploidy, symbiotic bacteriabearing host cells that are grouped into organ-like structures, called bacteriomes (Baumann 2005). The Fig. 1 panel A shows the results of the localization of the " $\mathrm{Ca}$. Portiera" in distinct egg stages. Endosymbiont probe signal was consistently observed in the distal segment of the egg corresponding to embryo pole (adjacent to the egg short stalk). This localization is suggestive of the potential maternal transmission of the endosymbiont to the embryo. In previous studies with $B$. tabaci, "Ca. Portiera" was detected mainly at the circumference of the bacteriocytes, which are located adjacent to the ovarioles (Gottlieb et al. 2006, 2008). "Ca. Portiera" is already known to be localized in association with the bacteriocytes in distinct whitefly populations (Guo et al. 2014) as shown at Fig. 1 panel A picture $\mathrm{b}$ and Fig. 1 Panel B shows the localization of " $\mathrm{Ca}$. Portiera" in female and male adults. Probe signals were observed in association with bacteriocytes. In female adults (Fig. 1 panel B picture a), the endosymbiont signal was found in the ovaries mainly in association with bacteriocytes. This same figure displays an egg within the female abdomen in close vicinity with bacteriocytes that seems to be colonized by " $\mathrm{Ca}$. Portiera". Moreover, a distinct signal quantity of "Ca. Portiera" was observed when comparing female and male adult samples (Fig. 1 panel B, pictures a and b). The corrected total cell fluorescence mean values were overall less in the male adult samples when compared with the values obtained from female adult samples under identical hybridization conditions, suggesting that " $\mathrm{Ca}$. Portiera" proliferate more efficiently in females (data not shown). This prokaryote is generally passed from host to host via vertical transmission (Feldhaar 2011). This vertical transmission of " $\mathrm{Ca}$. Portiera" is speculated to be due to the physical contact of the primordial eggs with bacteriocyte within the female abdomen. The association of this prokaryote with the egg region where the insect embryo is located give support to the hypothesis that this could be a major mechanism associated with its vertical transmission in our MEAM 1 population. 

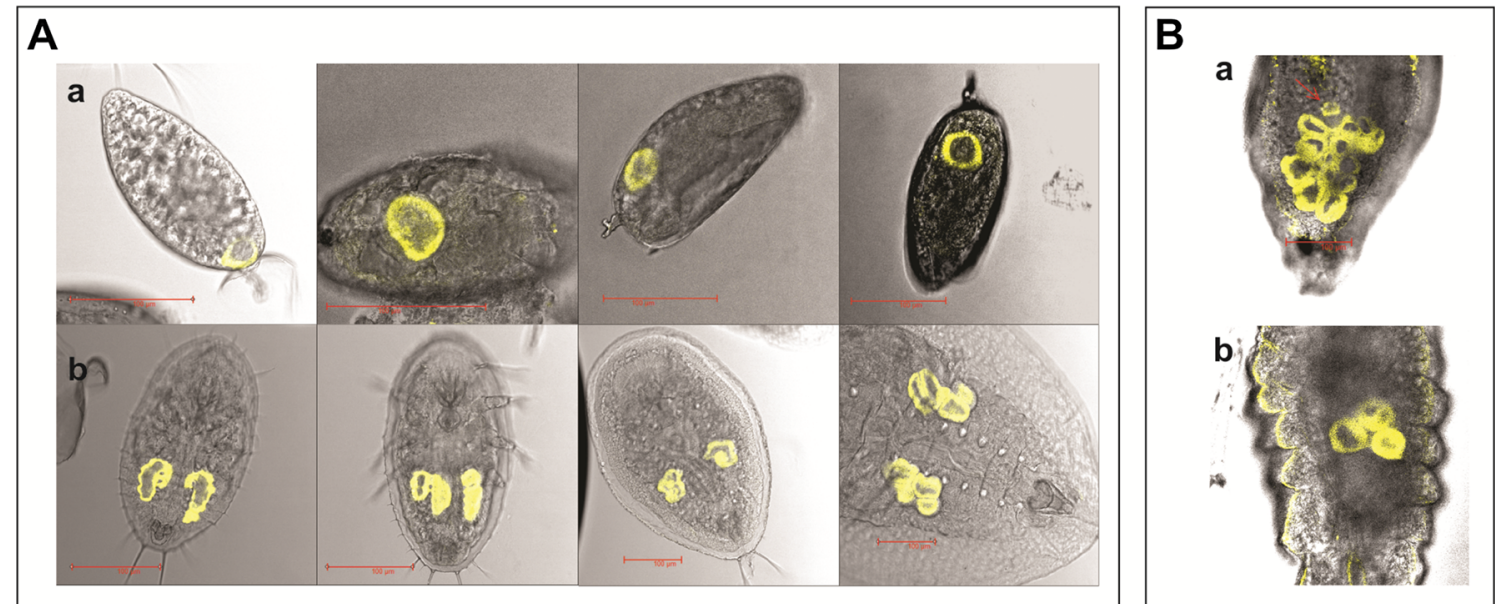

Fig. 1 Whole-mount fluorescence in situ hybridization of the obligate (primary) endosymbiont "Candidatus Portiera aleyrodidarum". (Panel a, sub-panel a) Bemisia tabaci MEAM 1 eggs and (Panel a, sub-panel $b$ ) nymphs; (Panel b, picture $a$ ) Bemisia tabaci MEAM 1 female and (Panel

\section{Localization of Wolbachia in the bodies of distinct developmental stages of the $B$. tabaci MEAM 1 population}

Signals derived from the Wolbachia-specific probe (W2-Cy5) were detected in B. tabaci eggs, nymphs, males, and females. Wolbachia-specific signals coincided with the female gonads at the tip of abdomen (Fig. 2 panel B, picture a). These signals were also found in close association with bacteriocytes in both

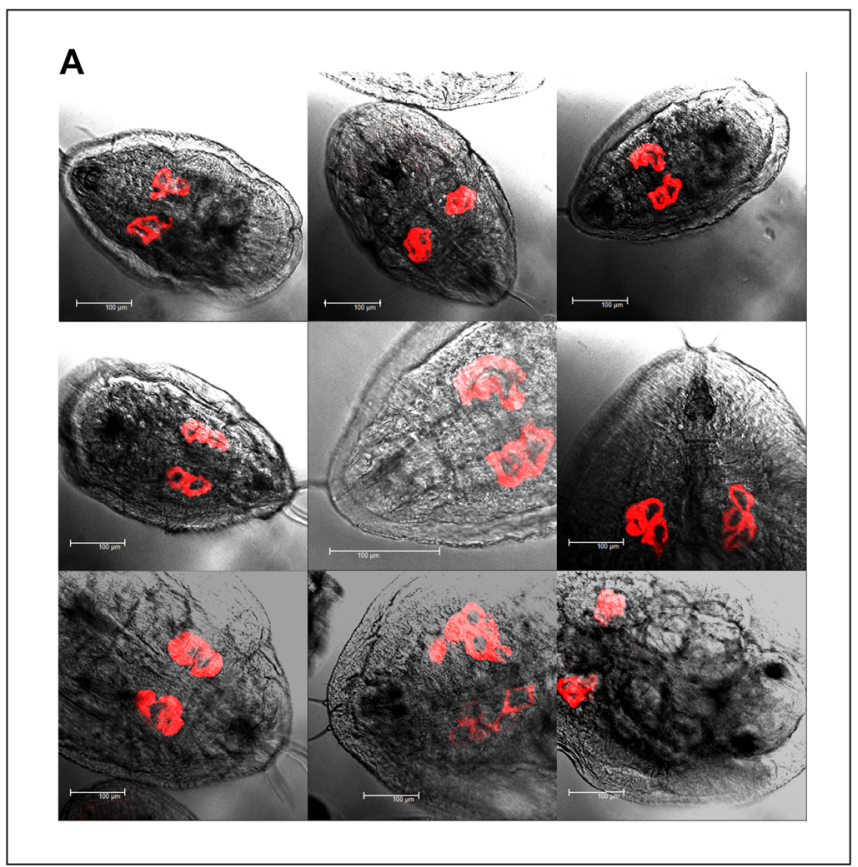

Fig. 2 Whole-mount fluorescence in situ hybridization using the specific-probe W2-Cy5 (pseudocolored red) of the secondary endosymbiont Wolbachia. Distinct nymphal stages of Bemisia tabaci MEAM 1 population from Brazil (Panel a); female (Panel b, picture $a$ ) and male (Panel b, picture $b$ ) samples of Bemisia tabaci MEAM 1. Panel b, picture $b$ ) male adults. The red arrow shows " $\mathrm{Ca}$. Portiera" in ovaries in association with bacteriocytes. Fluorescence signals were generated by the specific probe BTP1-Cy3 (pseudocolored yellow). Bars $=100 \mu \mathrm{m}$

nymphs (Fig. 2 Panel A) and male adults (Fig. 2 panel B, picture b). However, in some eggs, Wolbachia signals were not detected in strict association with bacteriocytes. A small fraction of the probe signal was also found scattered and diffuse throughout the egg in regions not clearly associated with bacteriocytes (Fig. 2 panel C, picture c). To our knowledge, this is a novel localization pattern described for Wolbachia in the Brazilian MEAM 1 population, since it was not observed
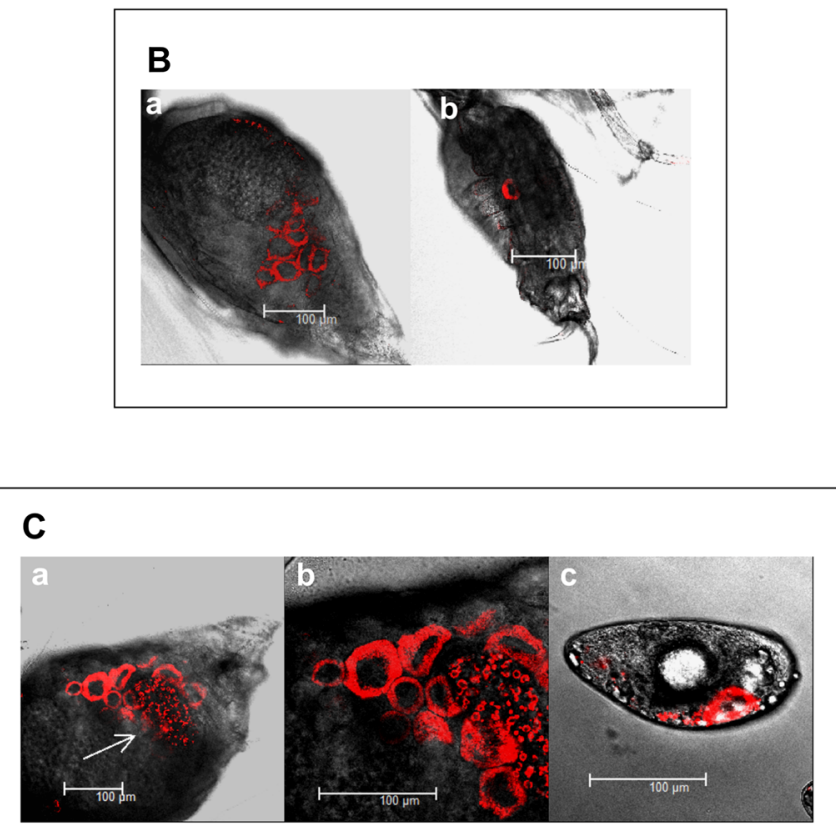

$\mathbf{c}$ (picture $b$ ) is a magnification of Panel $\mathbf{c}$ (picture $a$ ), illustrating that Wolbachia-specific signals were localized at the female gonads (at the tip of abdomen) in close association with bacteriocytes (white arrows). In some eggs, probe signals were not in strict association with bacteriocytes but also scattered in other areas (Panel c, picture $c$ ). Bars $=100 \mu \mathrm{m}$ 
in previous studies carried out with B. tabaci MED samples from Israel (Gottlieb et al. 2008). Interestingly, Gottlieb et al. (2008) detected Wolbachia signals outside the bacteriocytes in some $B$. tabaci MED Q adults. However, in eggs and nymphs the Wolbachia-specific signals were located exclusively at the circumference and/or inside bacteriocytes (Gottlieb et al. 2008). Biological differences between Wolbachia strains from Brazil and Israel could be an explanation for these variations. Genetic variability among Wolbachia populations from B. tabaci MED Q from China and Mediterranean regions has been identified (Ahmed et al. 2009). In fact, there are already reports of at least two distinct Wolbachia strains coexisting, for example, in closely related mulberry leafhopper species (Mitsuhashi et al. 2002). In our samples, Wolbachia was found at high frequency especially in eggs and nymphs, which is in contrast with the scenario described for MEAM 1 and MED Q field populations in China (Pan et al. 2012a). It is important to note that in Israel, Wolbachia association with bacteriocytes was found in B. tabaci MED Q individuals, but it was not found in MEAM 1 samples (Gottlieb et al. 2008). Moreover, Zchori-Fein et al. (2014) studied the variations in the symbiotic communities of B. tabaci over 2000 individuals from independent screenings. In this analysis, Wolbachia was again not detected in MEAM 1 individuals. Therefore, our report seems to be the first confirmation of Wolbachia in strong association with B. tabaci MEAM 1 individuals in the Neotropical areas.

\section{Co-localization of Wolbachia and "Ca. Portiera" in the bodies of distinct developmental stages of the Brazilian B. tabaci MEAM 1 population}

The results from several multiple images (Fig. 3 panels A from D) of each $B$. tabaci developmental stages indicated that " $\mathrm{Ca}$. Portiera" and Wolbachia are occupying the very same sites within nymphs, male, and female adults of their insect host. "Ca. Portiera" and Wolbachia signals were associated mainly with bacteriocytes. However, as previously discussed, in some eggs Wolbachia signals were also detected in scattered regions not in close association with bacteriocytes. The co-localization analysis using ImageJ (Coloc-2 plugin) estimated the Pearson's correlation coefficient value of 0.788 for eggs, of 0.802 for first instar nymphs, and of 0.875 for female adults, indicating that the intensity distribution between channels and, therefore, the coexistence of both probe-specific signals in a very close physical location. In addition, all the Pearson's correlation coefficient values showed a value significantly greater than zero, which was verified by using the Student's onesample $t$-test method. To verify the possibility of obtaining an improved double staining result, the concentration of the " $\mathrm{Ca}$. Portiera"-specific hybridization probe BTP1-Cy3 was 10 -fold increased. However, no significant increase of the fluorescence signal could be observed, possibly indicating that, under our experimental conditions, the hybridization of the second probe (the Wolbachia-specific W2-Cy5) is somehow favored in relation to that of " $\mathrm{Ca}$. Portiera". Quantitative PCR analysis to obtain a more precise estimation of the amount of each endosymbiont DNA occurring in female and male adults is left for future work.

\section{Localization of $\boldsymbol{H}$. defensa in the bodies of distinct developmental stages of the Brazilian B. tabaci MEAM 1 population}

The signals derived from the probe specific for the secondary endosymbiont $H$. defensa in $B$. tabaci were detected in male and female adults, eggs, and nymphs. $H$. defensa-specific signals were quite variable in terms of localization, being detected in the leg muscles (e.g., coxa), in the head (e.g., cibarium) (Fig. 4A) in the female ovaries (Fig. 4B) as well as at the abdomen tip corresponding to the reproductive organs of the males (Fig. 4C). Probe signals were observed at the tip as well as in the proximal abdomen segment (gonads) of the nymphs in association with bacteriocytes (Fig. 4D), but a less intense signal was also observed scattered within the eggs (Fig. 4E), indicating that Hamiltonella is not exclusively confined to bacteriocytes in this tomato MEAM 1 population. These results are in sharp contrast with that reported by Gottlieb et al. (2008).

Currently, works aiming to localize distinct endosymbiont genera associated with $B$. tabaci populations have been done mainly with MEAM 1 and MED Q species from the Old World (Gottlieb et al. 2006, 2008, 2010; Brown 2007). There is an overall lack of studies documenting the diversity as well as biological properties of the prokaryotic endosymbiont community associated with recent invasion of exotic $B$. tabaci MEAM 1 populations into Brazil. Gottlieb et al. (2008) investigated the localization of a group of endosymbionts in the MEAM 1 and MED Q species from Israel. These authors subdivided the bacterial flora of $B$. tabaci into two subgroups according to their localization within the host body: (1) endosymbionts with exclusive association with bacteriocytes and (2) endosymbionts not associated with bacteriocytes. " $\mathrm{Ca}$. Portiera" and $H$. defensa were found to be members of the first group, whereas Wolbachia and Cardinium were classified in the second group (Gottlieb et al. 2008). In the Brazilian B. tabaci MEAM 1 population employed in the present study, H. defensa and Wolbachia distribution in some developmental stages was not in complete agreement with the classification proposed by Gottlieb et al. (2008). This set of data reinforces the notion that localization and distribution of endosymbionts might vary according to the species/ecotype of occurrence of a given B. tabaci population. Previous work indicated that B. tabaci monopartite begomovirus transmission efficiency might be related to the diversity and relative composition of endosymbiont community living in association with the insect host (Gottlieb et al. 2010). 
Fig. 3 Co-localization of the primary endosymbiont "Candidatus Portiera aleyrodidarum" and the secondary endosymbiont Wolbachia in the tomato-infesting Bemisia tabaci MEAM 1 population from Brazil. " $\mathrm{Ca}$. Portiera" is shown in areas with green signals (generated by the specific-probe BTP1-Cy3, pseudocolored green) and Wolbachia is shown in areas with red signals (generated by the specific-probe W2-Cy5, pseudocolored red). Co-location signals (yellow) were observed mainly in bacteriocytes of female adult (Panel a), male adult (Panel b), nymphs (Panel c), and eggs (Panel d) samples. It was possible to visualize the auto-fluorescence of chitins on legs and wings. Bars $=100 \mu \mathrm{m}$

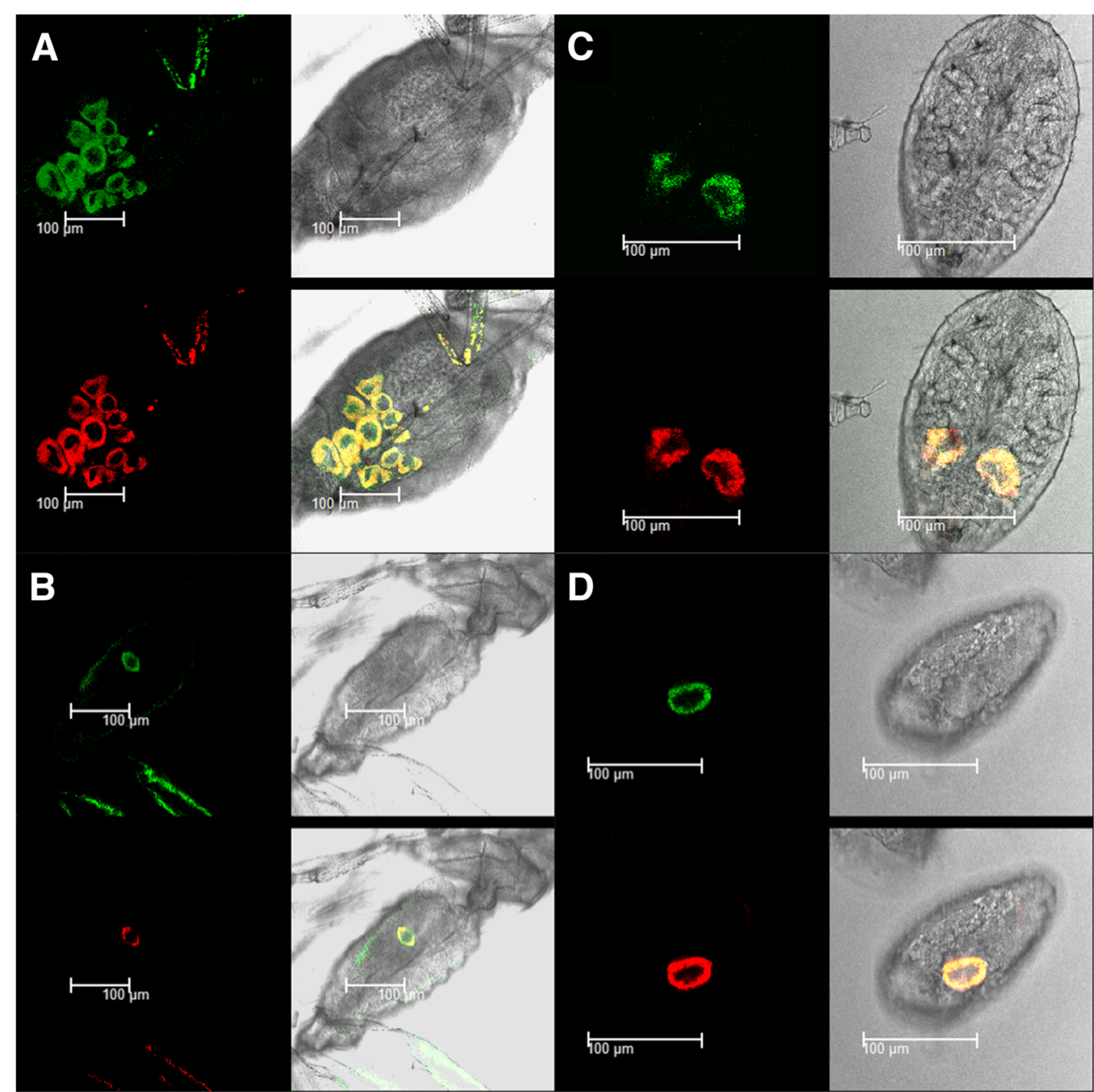

\section{Relative frequency and comparative analysis} of endosymbiont-specific fluorescence probe signals in distinct developmental stages and distinct genders of a Brazilian MEAM 1 population

Probe-specific signals of all three endosymbionts visualized in distinct developmental stages were overall more frequently detected in nymphs and eggs (Table 3). Female samples displayed higher infection percentages and higher levels of colonization when compared with male adult samples. In addition, we observed that the amount of all three bacteria was overall lower in the male adult samples when compared with the female samples (Fig. 1 panel B, 2 panel B). In our study, Wolbachia was found with relative frequency and at detectable levels within the body of male and female adults in the B. tabaci MEAM 1 population. This somewhat surprising occurrence of Wolbachia in the Brazilian B. tabaci MEAM 1 population may have significant epidemiological impacts. Is
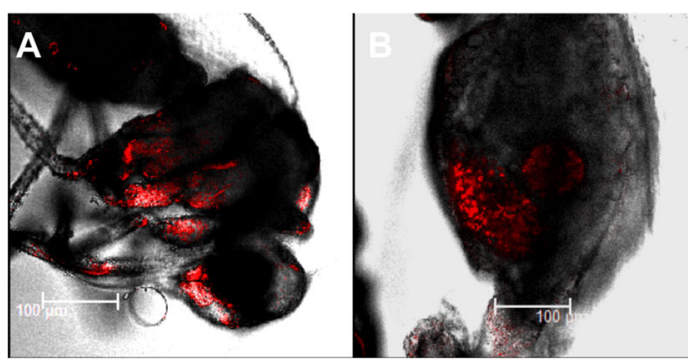

Fig. 4 Whole-mount fluorescence in situ hybridization using specificprobe BTH-Cy5 (pseudocolored red) of the facultative (secondary) endosymbiont $H$. defensa in a representative Bemisia tabaci MEAM 1 population from tomatoes in Brazil. $H$. defensa-specific signals were

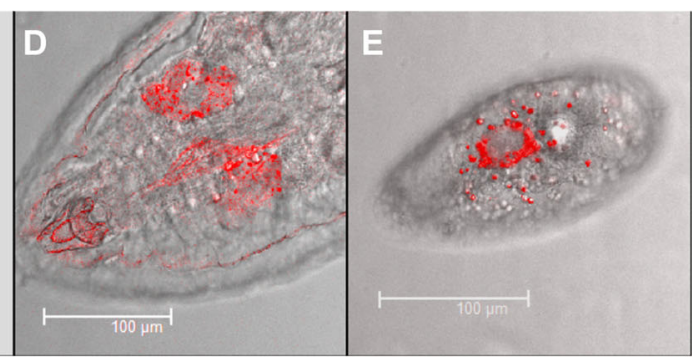

localized in a the male leg muscles, in the head mouthparts, in $\mathbf{b}$ the female ovaries, $\mathbf{c}$ male reproductive organs at the abdomen tip, $\mathbf{d}$ distal tips and in the proximal abdomen segment of the nymphs, and $\mathbf{e}$ in the bacteriocytes but also scattered into the eggs. Bars $=100 \mu \mathrm{m}$ 
important to point out that other secondary endosymbionts (e.g., Wolbachia) were also found playing a key role in increasing rates of monopartite begomovirus transmission by MED Q populations (Gottlieb et al. 2010). In fact, it is quite possible that GroEL proteins might be begomovirus-specific or even virus strain-specific. In Brazil, so far only bipartite begomovirus species have been detected in tomato and other crops (Ribeiro et al. 2003; Fernandes et al. 2008; Fernandes 2010), with exception for sweet-potatoes where solely monopartite species were detected (Paprotka et al. 2010). In this scenario, it would be of interest to carry out additional studies aiming to demonstrate if the localization of the endosymbionts and their gene products might be correlated with the transmission ability/efficiency by the Brazilian MEAM 1 populations of the complex of more than 20 bipartite begomovirus species described infecting tomatoes so far (Ribeiro et al. 2003; Fernandes et al. 2008; Fernandes 2010).

In conclusion, our results represent the first set of analyses about the interactions that are occurring among endosymbiont genera and a representative tomato-infesting $B$. tabaci MEAM 1 population from the Neotropics. All endosymbionts were found in our samples, revealing the occurrence of distinct and novel infection and colonization patterns. " $\mathrm{Ca}$. Portiera" was located exclusively at the circumference and/or inside bacteriocytes as expected. However, a peculiar sub-localization pattern was observed for $H$. defensa and for Wolbachia in eggs. Strong $H$. defensa-specific probe signals were detected in the head and in the region associated with the male reproductive organs, which is in sharp contrast with previous studies (Marubayashi et al. 2014), which found this bacterium always confined to the bacteriosome in MEAM 1 and New World 2 species from Brazil. In addition, our results reinforced the notion that $H$. defensa is also associated with $B$. tabaci MEAM 1 population. On the other hand, Wolbachia infection/colonization (which is associated with MED and rarely found in MEAM 1 populations from the Old World) was present at high frequency in eggs and nymphs. All these features are new and reported for the first time in the Brazilian whitefly population.

There is a clear need for further investigations on the interactions among Brazilian bipartite begomoviruses, viruliferous whiteflies and secondary endosymbionts, with special emphasis on key prokaryotic genera such as $H$. defensa and, according to our results, also Wolbachia. These additional studies will be necessary in order to elucidate their function in this complex multi-kingdom (tomato - insect vector species Begomovirus species - prokaryotic endosymbionts) interaction (Brown 2007) under Neotropical conditions.

Acknowledgments This work was supported by a joint Grant 564633/ 2010-0 CNPq (Conselho Nacional de Desenvolvimento Científico e Tecnológico) and CAPES (Conselho de Aperfeiçoamento de Pessoal de Nível Superior) and Grant 2009/00102-2 from FAP-DF (Fundação de Apoio a Pesquisa do Distrito Federal).

\section{References}

Ahmed MZ, Shatters RG, Ren SX, Jin GH, Mandour NS, Qiu BL (2009) Genetic distinctions among the Mediterranean and Chinese populations of Bemisia tabaci Q biotype and their endosymbiont Wolbachia populations. J Appl Entomol 133:733-741

Ahmed MZ, Ren SX, Xue X, Li XX, Jin GH, Qiu BL (2010) Prevalence of endosymbionts in Bemisia tabaci populations and their in vivo sensitivity to antibiotics. Curr Microbiol 61:322-328

Ahmed MZ, De Barro PJ, Ren SX, Greeff JM, Qiu BL (2013) Evidence for horizontal transmission of secondary endosymbionts in the Bemisia tabaci cryptic species complex. PLoS ONE 8:e53084

Aljanabi SM, Martinez I (1997) Universal and rapid salt-extraction of high quality genomic DNA for PCR-based techniques. Nucleic Acids Res 25:4692-4693

Baumann P (2005) Biology of bacteriocyte-associated endosymbionts of plant sap-sucking insects. Annu Rev Microbiol 59:155-189

Baumann P, Munson MA, Lai CY, Clark MA, Bauman L, Moran NA, Campbell BC (1993) Origin and properties of bacterial endosymbionts of aphids, whiteflies, and mealybugs. Am Soc Microbiol News 59:21-24

Bensadia F, Boudreault S, Guay JF, Michaud D, Cloutier C (2005) Aphid clonal resistance to a parasitoid fails under heat stress. J Insect Physiol 52:146-157

Berry SD, Fondong VN, Rey C, Rogan D, Fauquet CM, Brown JK (2004) Molecular evidence for five distinct Bemisia tabaci (Homoptera: Aleyrodidae) geographic haplotypes associated with cassava plants in Sub-Saharan Africa. Entomol Soc Am 97:852-859

Bing XL, Yang J, Zchori-Fein E, Wang XW, Liu SS (2013) Characterization of a newly discovered symbiont of the whitefly Bemisia tabaci (Hemiptera: Aleyrodidae). Appl Environ Microbiol 79:569-575

Boiteux LS, Fonseca MEN, Simon PW (1999) Effects of plant tissue and DNA purification method on randomly amplified polymorphic DNA-based genetic fingerprinting analysis in carrot. J Am Soc Hortic Sci 124:32-38

Braquart-Varnier C, Lachat M, Herbinière J, Johnson M, Caubet Y, Bouchon D, Sicard M (2008) Wolbachia mediate variation of host immunocompetence. PLoS ONE 3:e3286

Brown JK (2007) The Bemisia tabaci complex: Genetic and phenotypic variability drives begomovirus spread and virus diversification. Online. APSnet Features doi: 10.1094/APSnetFeature-2007-0107. Accessed on August 2014

Buchner P (1965) Endosymbiosis of Animals with Plant Microorganisms. Wiley, New York

Chiel E, Gottlieb Y, Zchori-Fein E, Mozes-Daube N, Katzir N, Inbar M, Ghanim M (2007) Biotype-dependent secondary symbiont communities in sympatric populations of Bemisia tabaci. Bull Entomol Res 97:407-413

Chiel E, Inbar M, Mozes-Daube N, White JA, Hunter MS, Zchori-Fein E (2009) Assessments of fitness effects by the facultative symbiont Rickettsia in the sweetpotato whitefly (Hemiptera: Aleyrodidae). Ann Entomol Soc Am 102:413-418

Chu D, Gao CS, De Barro P, Zhang YJ, Wan FH, Khan IA (2011) Further insights into the strange role of bacterial endosymbionts in whitefly, Bemisia tabaci: Comparison of secondary symbionts from biotypes B and Q in China. Bull Entomol Res 101:477-486

Clark MA, Bauman L, Munson MA, Bauman P, Campbell BC, Duffus JE, Osborne LS, Moran NA (1992) The eubacterial endosymbionts of whiteflies (Homoptera: Aleyrodidae) constitue a lineage distinct from the endosymbionts of aphids and mealybugs. Curr Microbiol 25:119-123

Costa AS, Costa CL, Sauer HFG (1973) Surto de mosca branca em culturas do Paraná e São Paulo. Anais da Soc Entomol do Brasil $1: 20-30$ 
De Barro PJ, Liu SS, Boykin LM, Dinsdale AB (2011) Bemisia tabaci: a statement of species status. Annu Rev Entomol 56:1119

Dinsdale A, Cook L, Riginos C, Buckley YM, De Barro P (2010) Refined global analysis of Bemisia tabaci (Hemiptera: Sternorrhyncha: Aleyrodoidea: Aleyrodidae) mitochondrial cytochrome oxidase 1 to identify species level genetic boundaries. Ann Entomol Soc Am 103:196-208

Everett KD, Thao M, Horn M, Dysynski GE, Baumann P (2005) Novel chlamydiae in whiteflies and scale insects: endosymbionts 'Candidatus Fritschea bemisiae' strain Falk and 'Candidatus Fritschea eriococci' strain Elm. Int J Syst Evol Microbiol 55: $1581-1587$

Feldhaar H (2011) Bacterial symbionts as mediators of ecologically important traits of insect hosts. Ecol Entomol 36:533-543

Fernandes NAN (2010) Variabilidade genômica e geográfica de espécies de begomovírus em tomateiro e em dois gêneros de plantas daninhas no Brasil. MSc. in Fitopatology, University of Brasília

Fernandes FR, Albuquerque LC, Giordano LB, Boiteux LS, De Ávila AC, Inoue-Nagata AK (2008) Diversity and prevalence of Brazilian bipartite begomovirus species associated to tomatoes. Virus Genes $36: 251-258$

Ferrari J, Darby AC, Daniell TJ, Godfray HCJ, Douglas AE (2004) Linking the bacterial community in pea aphids with host-plant use and natural enemy resistance. Ecol Entomol 29:60-65

Gottlieb Y, Ghanim M, Chiel E, Gerling D, Portnoy V, Steinberg S, Tzuri G, Horowitz AR, Belausov E, Mozes-Daube N, Kontsedalov S, Gershon M, Gal S, Katzir N, Zchori-Fein E (2006) Identification and localization of a Rickettsia sp. in Bemisia tabaci (Homoptera: Aleyrodidae). Appl Environ Microbiol 72:3646-3652

Gottlieb Y, Ghanim M, Gueguen G, Kontsedalov S, Vavre F, Fleury F, Zchori-Fein E (2008) Inherited intracelular ecosystem: symbiotic bacteria share bacteriocytes in whiteflies. FASEB J 22:2591-2599

Gottlieb Y, Zchori-Fein E, Mozes-Daube N, Kontsedalov S, Skaljac M, Brumin M, Sobol I, Czosnek H, Vavre F, Fleury F, Ghanim M (2010) The transmission efficiency of Tomato yellow leaf curl virus by the whitefly Bemisia tabaci is correlated with the presence of a specific symbiotic bacterium species. J Virol 84:9310-9317

Guo H, Qu Y, Liu X, Zhong W, Fang J (2014) Female-biased symbionts and Tomato yellow leaf curl virus infections in Bemisia tabaci. PLoS ONE 9:e84538

Hasegawa M, Kishino H, Yano T (1985) Dating of the human-ape splitting by a molecular clock of mitochondrial DNA. J Mol Evol 22: $160-174$

Holden PR, Brookfiel FYJ, Jones P (1993) Cloning and characterization of an ftsZ homologue from a bacterial symbiont of Drosophila melanogaster. Mol Gen Genet 240:213-220

Jiang ZF, Xia F, Johnson KW, Brown CD, Bartom E, Tuteja JH, Stevens R, Grossman RL, Brumin M, White KP, Ghanim M (2013) Comparison of the genome sequences of "Candidatus Portiera aleyrodidarum" primary endosymbionts of the whitefly Bemisia tabaci B and Q biotypes. Appl Environ Microbiol 79:1757-1759

Kontsedalov S, Zchori-Fein E, Chiel E, Gottlieb Y, Inbar M, Ghanim M (2008) The presence of Rickettsia is associated with increased susceptibility of Bemisia tabaci (Homoptera: Aleyrodidae) to insecticides. Pest Manag Sci 64:789-792

Lee W, Park J, Lee GS, Lee S, Akimoto SI (2013) Taxonomic status of the Bemisia tabaci complex (Hemiptera: Aleyrodidae) and reassessment of the number of its constituent species. PLoS ONE 8:e63817

Marubayashi JM, Yuki VA, Rocha KCG, Mituti T, Pelegrinotti FM, Ferreira FZ, Moura MF, Navas-Castillo J, Moriones E, Pavan MA MA, Krause-Sakate R (2013) At least two indigenous species of the Bemisia tabaci complex are present in Brazil. J Appl Entomol 137: $113-121$

Marubayashi JM, Kliot A, Yuki VA, Rezende JAM, Krause-Sakate R, Pavan MA, Ghanim M (2014) Diversity and localization of bacterial endosymbionts from whitefly species collected in Brazil. PLoS ONE. doi:10.1371/journal.pone. 0108363

McDonald JH, Dunn K (2013) Statistical tests for measures of colocalization in biological microscopy. J Microsc 252:295-302

Min KT, Benzer S (1997) Wolbachia, normally a symbiont of Drosophila, can be virulent, causing degeneration and early death. Proc Natl Acad Sci U S A 94:10792-11079

Mitsuhashi W, Saiki T, Wei W, Kawakita H, Sato M (2002) Two novel strains of Wolbachia coexisting in both species of mulberry leafhoppers. Insect Mol Biol 11:577-584

Moran N, Baumann P (1994) Phylogenetic of cytoplasmically inherited microorganisms of arthropod. Trends Ecol Evol 9:15-20

Moran NA, Plague GR, Sandstrom JP, Wilcox JL (2003) A genomic perspective on nutrient provising by bacterial symbionts of insects. Proc Natl Acad Sci U S A 100:14543-14548

Navas-Castillo J, Fiallo-Olivé E, Sánchez-Campos S (2011) Emerging virus diseases transmitted by whiteflies. Annu Rev Phytopathol 49:219-248

Nirgianaki A, Banks GK, Frohlich DR, Veneti Z, Braig HR, Miller TA, Bedford ID, Markham PG, Savakis C, Bourtzis K (2003) Wolbachia infections of the whitefly Bemisia tabaci. Curr Microbiol 47:93-101

Pan H, Li X, Ge D, Wang S, Wu Q, Xie W, Jiai X, Chu D, Liu B, Xu B, Zhang Y (2012a) Factors affecting population dynamics of maternally transmitted endosymbionts in Bemisia tabaci. PLoS ONE 7: e30760

Pan HP, Li X, Zhang Y (2012b) Sex affects the infection frequencies of symbionts in Bemisia tabaci. Commun Integr Biol 5:337-339

Paprotka T, Boiteux LS, Fonseca MEN, Resende RO, Jeske H, Faria JC, Ribeiro SG (2010) Genomic diversity of sweet potato geminiviruses in a Brazilian germplasm bank. Virus Res 149:224-233

Ribeiro SG, Melo LV, Boiteux LS, Kitajima EW, Faria JC (1994) Tomato infection by a geminiviruses in the Federal District, Brazil. Fitopatol Bras 19(Supl):330

Ribeiro SG, Ambrozevícius LP, De Ávila AC, Bezerra IC, Calegário RF, Fernandes JJ, Lima MF, de Mello RN, Rocha H, Zerbini FM (2003) Distribution and genetic diversity of tomato-infecting begomovirus in Brazil. Arch Virol 148:281-295

Ronquist F, Huelsenbeck JP (2003) MRBAYES 3: Bayesian phylogenetic inference under mixed models. Bioinformatics 19:1572-1574

Ruan Y-M, Xu J, Liu S-S (2006) Effects of antibiotics on fitness of the B biotype and a non-B biotype of the whitefly Bemisia tabaci. Entomol Exp Appl 121:159-166

Santos CDG, De Ávila AC, Resende RO (2003) Estudo da interação de um begomovirus isolado de tomateiro com a mosca branca vetora. Fitopatol Bras 28:664-673

Santos-Garcia D, Farnier PA, Beitia F, Zchori-Fein E, Vavre F, Mouton L, Moya A, Latorre A, Silva FJ (2012) Complete genome sequence of "Candidatus Portiera aleyrodidarum" BT-QVLC, an obligate symbiont that supplies amino acids and carotenoids to Bemisia tabaci. J Bacteriol 194:6654-6655

Simon C, Frati F, Beckembach A, Crespi B, Liu H, Flook P (1994) Evolution, weighting and phylogenetic utility of mitochondrial gene sequences and a compilation of conserved polymerase chain reaction primers. Ann Entomol Soc Am 87:651-701

Škaljac M, Zanic K, Ban SG, Kontsedalov S, Ghanim M (2010) Coinfection and localization of secondary symbionts in two whitefly species. BMC Microbiol 10:142

Škaljac M, Žanić K, Hrnčić S, Radonjić S, Perović T, Ghanim M (2013) Diversity and localization of bacterial symbionts in three whitefly species (Hemiptera: Aleyrodidae) from the east coast of the Adriatic Sea. Bull Entomol Res 103:48-59

Su Q, Xie W, Wang S, Wu Q, Liu B, Fang Y, Xu B, Zhang Y (2014) The endosymbiont Hamiltonella increases the growth rate of its host Bemisia tabaci during periods of nutritional stress. PLoS ONE 9: e89002 
Tamura K, Stecher G, Peterson D, Filipski A, Kumar S (2013) MEGA6: molecular evolutionary genetics analysis version 6.0. Mol Biol Evol 30:2725-2729

Thao ML, Baumann P (2004) Evidence for multiple acquisition of Arsenophonus by whitefly species (Sternorrhyncha: Aleyrodidae). Curr Microbiol 48:140-144

Thompson WMO (2011) Introduction: Whiteflies, Geminiviruses and recent events, (Chapter 1). In: Thompson WMO (ed) The Whitefly, Bemisia tabaci (Homoptera: Aleyrodidae) interaction with Geminivirus-infected host plants. Springer Science Business Media B.V, Dordrecht, p 381

Thompson JD, Higgs DG, Gibson TJ (1994) CLUSTAL W: improving the sensitivity of progressive multiple sequence alignment through sequence weighting, position-specific gap penalties and weight matrix choice. Nucleic Acids Res 22:4673-4680

Weeks AR, Velten R, Stouthamer R (2003) Incidence of a new sex-ratiodistorting endosymbiotic bacterium among arthropods. Proc R Soc B Biol Sci 270:1857-1865

Zchori-Fein E, Brown JK (2002) Diversity of prokaryotes associated with Bemisia tabaci (Gennadius) (Hemiptera: Aleyrodidae). Ann Entomol Soc Am 95:711-718

Zchori-Fein E, Lahav T, Freilich S (2014) Variations in the identity and complexity of endosymbiont combinations in whitefly hosts. Front Microbiol 5:1-7

Zhou W, Rousset F, O'Neill S (1998) Phylogeny and PCR-based classification of Wolbachia strains using wsp gene sequences. Proc R Soc B Biol Sci 265:509-515 